\title{
Development of construction waste management
}

\author{
Aleksandr Aleksanin * \\ Moscow State University of Civil Engineering, Yaroslavskoe shosse, 26, Moscow, 129337, Russia
}

\begin{abstract}
Improvement of building materials, optimization and development of technological processes of construction production require the development of promising areas of research to improve the efficiency of management of construction waste, which will provide economic and environmental benefits. The article provides statistical data on the volumes of formation and processing of construction and demolition waste, confirming the relevance and need for attention to the area of construction waste disposal. To improve the efficiency of construction and demolition waste management processes, it is proposed to create specialized centers that perform specific functions of coordinating material and information resources, which will track and coordinate the entire life cycle of waste from the source of education to the place of disposal or recycling. To improve the efficiency of processes for optimizing the management of construction waste, it is proposed to attract to them the organizational, economic and technological capabilities of private business.
\end{abstract}

\section{Introduction}

Today, the construction industry is actively developing, major repairs, reconstruction and renovation of residential, public and industrial facilities are underway. In connection with the constant increase in the number of buildings under construction and demolished, the amount of construction waste is growing, most of which has the potential of secondary use, is a secondary material resource [1-3]. Organizing the orderly handling of construction waste is one of the most important environmental and resource-saving problems. In many countries, there are no streamlined systems for the collection, disposal, recycling and recycling of construction waste [4-8].

The problem of waste management is in line with the tasks of protecting the hydrosphere and the atmosphere from pollution, issues of conservation of biological and land resources. In the natural environment, non-decaying waste is constantly accumulated, which leads to the need for the constant removal of new land plots for burial sites, and also requires the reclamation of contaminated areas in mothballed landfills and landfills. In the process of waste management, it is necessary to pay attention not only to the quantitative characteristics of the waste (production volumes), but also to quality indicators (hazard classes) [9-13].

\footnotetext{
* Corresponding author: aleks08007@ mail.ru
} 
Despite the global financial crises, people will need housing, industrial and cultural buildings at any time. Every year in the world the population of large cities is growing, which makes it necessary to increase the volume of housing construction. It is not surprising that for developing cities the removal, processing and disposal of construction waste becomes one of the most pressing problems $[14 ; 15]$.

\section{Theoretical Basis}

According to the statistics presented in Figure 1, construction waste in the Russian Federation almost doubled from 2010 to 2016 [16]. The volume of construction and demolition waste increased every year, the largest jump was in the period 2015-2016, when the amount of waste increased by 4 million tons.

\begin{tabular}{|c|c|c|c|c|c|c|c|c|}
\hline Activities & $2010 y$. & $2011 \mathrm{y}$. & $2012 y$. & 2013 y. & $2014 \mathrm{y}$ & $2015 \mathrm{y}$ & $2016 \mathrm{y}$. & $2017 \mathrm{y}$ \\
\hline Total, million tons & 3734,7 & 4303,3 & 5007,9 & 5152,8 & 5168,3 & 5060,2 & 5441,3 & 6220,6 \\
\hline extraction of mineral resources & 3334,6 & 3818,7 & 4629,3 & 4701,2 & 4807,3 & 4653,0 & 4723,8 & 5786,2 \\
\hline $\begin{array}{l}\text { provision of electric energy, gas and steam; air } \\
\text { conditioning; water supply, water disposal, waste } \\
\text { collection and disposal, pollution control activities }\end{array}$ & 68,0 & 58 & 28,4 & 24,1 & 28,3 & 26,4 & 27,7 & 30,5 \\
\hline construction & 11,1 & 14,1 & 14,6 & 16,7 & 17,6 & 17,1 & 21,1 & - \\
\hline
\end{tabular}

Fig. 1. Production and consumption waste generation by economic activity in the Russian Federation, 2010-2017, million tons.

The published report "on the state of the environment in the city of Moscow in 2017" contains information on the formation of 6.95 million tons of construction waste and more than 20 million tons of construction soil [17]. The dynamics of construction and demolition wastes, construction soils are presented in Figure 2. According to this document, almost all construction and demolition wastes are recycled, that is, reused. Most of the construction waste generated on the territory of Moscow is disposed of at landfills and open pit mines as an insulating and recultivating material. In 2017, the construction waste recycling industry was actively developing to produce recycled materials. Construction waste processing facilities are developing in the city with the creation of recycled rubble, which is reused in construction activities. There is a great potential for using construction waste to create different types of products. Modern technologies of demolition and recycling allow to involve in the secondary circulation more than $80 \%$ of construction waste.

Abu Dhabi has developed a plan for 2016-2020 to preserve environmental safety in the region. Within the framework of this document, a special program has been created, the goal of which is to achieve integrated management of construction waste. By 2020, more than $60 \%$ of waste should be recycled and used as secondary raw materials. The total amount of the waste generated in Abu Dhabi has been rapidly varying in recent years. The official figure for 2016 was about 9.6 million tonnes of solid waste produced. The vast majority of waste, about $47 \%$ (fig. 3 ), came from many construction and demolition sites concentrated in and around the vibrant Abu Dhabi City area itself. Al Dhafra Recycling industries was Established in December 2008 and operated in May 2010, in Abu Dhabi Emirate. Al Dhafra Recycling Industries is responsible for the processing of waste materials across the emirate of Abu Dhabi, excluding Al Ain [18]. 


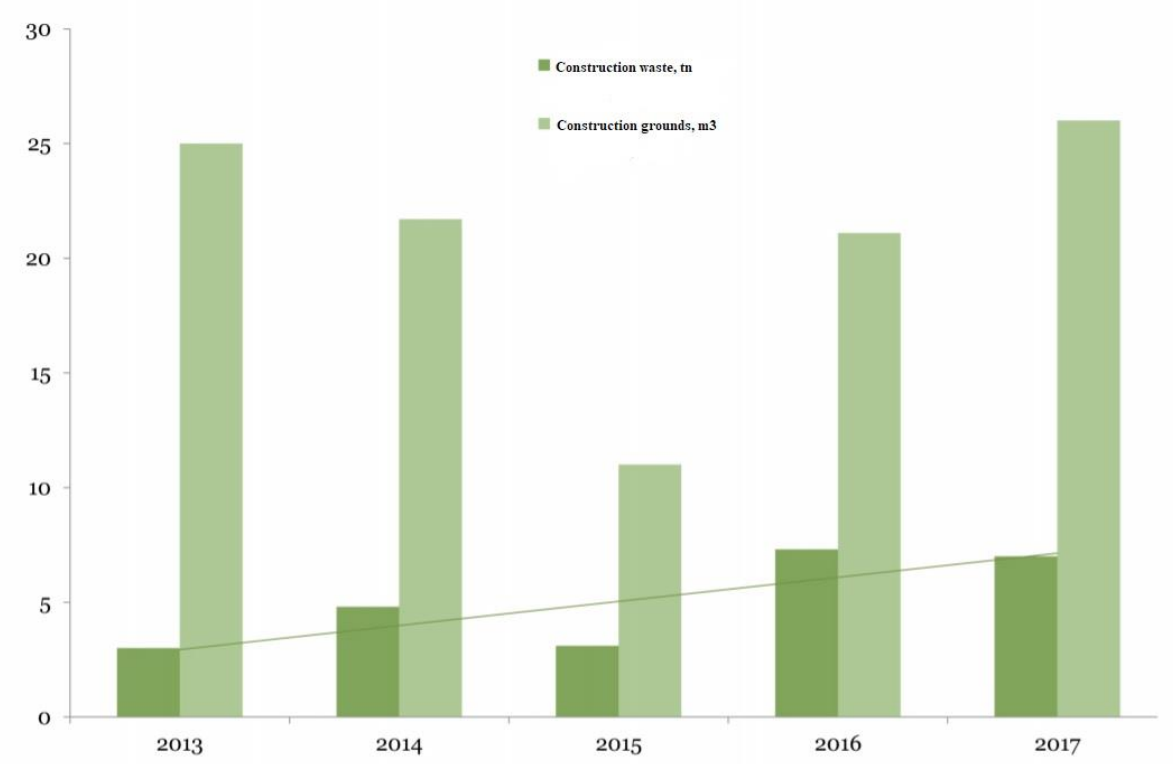

Fig. 2. Dynamics of formation of construction waste and ground in the city of Moscow

The aim of the plant is to reduce the level of construction and demolition waste material being disposed in Abu Dhabi's landfill. All waste materials sent to the recycling plant are inspected for sustainability before processing. Metal and other unsuitable materials are extracted before diverting the construction and demolition material to the processing plant, where the material is crushed to create $100 \%$ recycled aggregates and asphalt, which have approved specifications of well graded $37.5-0 \mathrm{~mm}$ base coarse and sub-base.

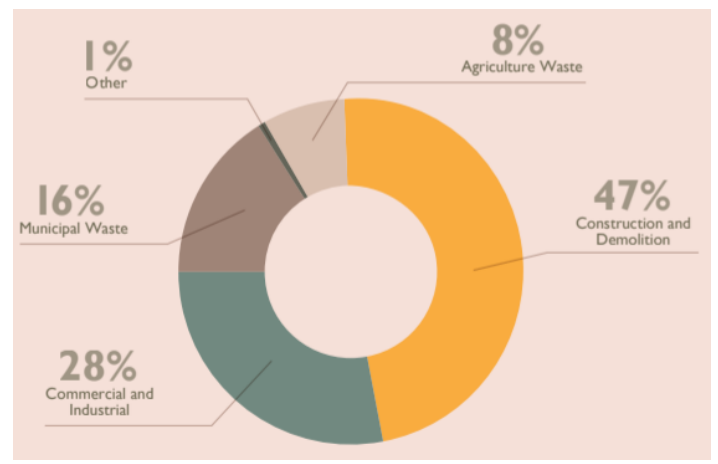

Fig. 3. Percentage distribution of non-hazardous solid waste by source activity in Abu Dhabi, 2016

Great attention is paid to the recycling and reuse of construction waste in Hong Kong (Fig. 4). The quantity of overall construction waste disposed of at landfills in 2016 was 4,422 tpd (1.62 million tonnes), which has increased by $5.3 \%$ as compared to 2015 . The increase was consistent with the increase in construction work in Hong Kong. In recent years, the reuse rate of inert materials sorted out from construction waste has remained at above $90 \%$, and was $93 \%$ in 2016 . These materials were delivered to the public fill reception facilities and other outlets for beneficial direct reuse. The increase in construction waste disposal charges, with effect from April 2017, is expected to provide further incentives for the trade to reduce and reuse construction waste [19]. 


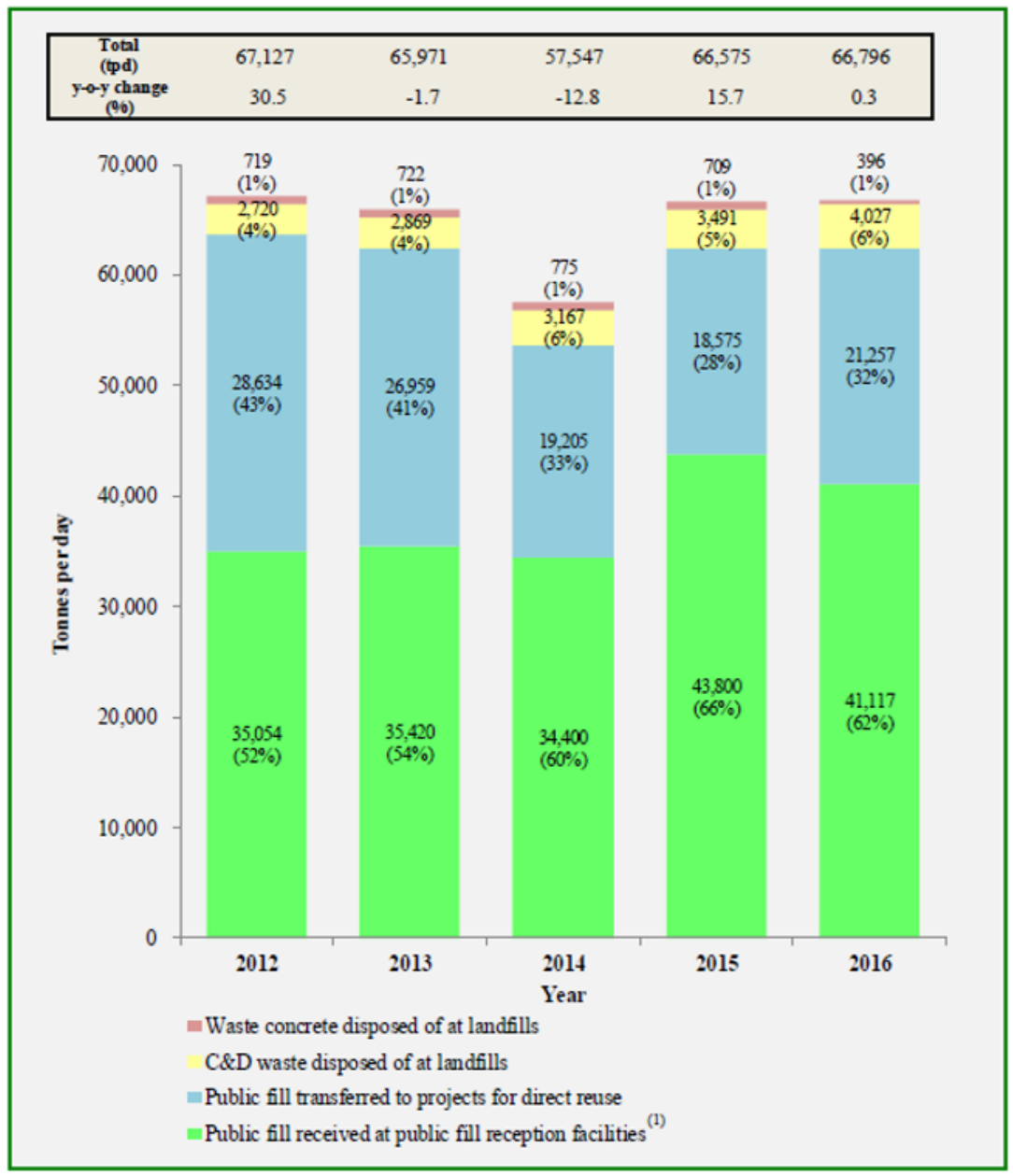

Fig. 4. Disposal and reuse of overall construction waste from 2012 to 2016 in Hong Kong

\section{Results and Discussion}

To improve the efficiency of construction and demolition waste management processes, it is proposed to create specialized centers that perform specific functions of coordinating material and information resources, which will track and coordinate the entire life cycle of waste from the source of education to the place of disposal or recycling. The most effective is the implementation of integrated centers that provide the full range of services for the management of construction waste, including:

- waste processing and receiving from them secondary raw materials;

- provision of specialized equipment for waste transportation, as well as machines for demolishing buildings and structures;

- informatization and scheduling of the process of management of construction waste in the region.

Complex centers should be located at the intersections of major highways and in the regions where construction is developing at the most intensive rates, demolishing old structures that do not meet modern human needs. At the same time, there should be a shortage of waste treatment enterprises in the region, otherwise it will not be possible to 
ensure full utilization of new capacities in the logistics center [20-22].

Many construction contractors during the dismantling work face the problem of the lack of specialized equipment for demolishing buildings and structures. This problem is especially critical in small urban settlements. The presence of an integrated center with its own fleet of machines and equipment for dismantling will allow construction companies to significantly save time and money on finding and renting similar equipment in neighboring areas.

The list of services of the complex center may include transportation of construction waste from the place of education to the point of reception or processing. The presence of a fleet of trucks and the provision of transport services will allow the center to ensure the timely removal of waste from construction sites. Implementation of the selection of vehicles with optimal characteristics of the loading bunker by specialists of the integrated center will reduce the economic losses from incomplete loading of vehicles.

One of the main services of the integrated logistics center will be the recycling of construction waste into secondary raw materials. The centralization of waste treatment plants on the territory of the center will ensure a constant utilization of their production capacity, will allow improving processing methods and expanding the range of waste accepted for recycling.

The complex center should include not only crushing plants that process reinforced concrete building scrap resulting from the demolition of buildings and structures (reinforced concrete floor slabs, reinforced concrete wall panels, landings and marches). On its territory, it is necessary to provide for a full complex of recycling construction and demolition waste, which includes technologies for processing bitumen-containing coatings, waste wood and polymeric materials.

On the basis of complex centers, it is advisable to create our own research and experimental laboratories that will be engaged in the development of technological processes for the recycling of construction waste into secondary raw materials, as well as information support for the life cycle of construction waste. Today, the technology of building information modeling (BIM) is actively developing, which can significantly reduce the amount of waste in construction. This is possible when it is implemented at the design stage to avoid irrational design decisions, collisions, etc. Information data transfer systems allow for the prompt exchange of information between project participants, timely warning of changes in space-planning decisions, materials, structures and equipment.

It is possible to increase the efficiency of creating integrated centers by attracting to them the organizational, economic and technological opportunities of private business. There is no doubt that the development and introduction of modern methods and technologies for the production of secondary raw materials from waste will require significant investments. This problem can be solved by attracting the maximum number of private investment organizations to the sphere of construction waste, which will significantly reduce the burden on the budgets of regional, regional and municipal levels.

The use of mechanisms of interaction between the state and private business in conjunction with the use of the resource potential of construction waste is a promising area of research. This type of interaction for the development of an effective market economy, as well as solving socially significant tasks, began to take the form of a partnership between the state and private entrepreneurs in foreign countries Public-Private Partnership.

The model of public-private partnership originated in the UK, where within its framework more than 700 projects have been implemented so far. Public-private partnership has become widespread in the countries of the European Union, the USA, Canada, etc.

The level of business activity of private business in the field of construction waste management can be significantly increased through partnerships with the state, which is 
able to create favorable conditions for the effective functioning of large industries, as well as to support the sustainable development of entrepreneurship.

The combination of mechanisms of state regulation and stimulation of the economy with the efforts of private investors in the field of obtaining secondary raw materials from construction waste will make it possible to accelerate the development of the wasteprocessing industry in the country [23-25].

There are several main interrelated activities, the implementation of which is able to breathe new life into the organization of recycling construction waste:

- organization of direct state financing of priority projects in the field of waste processing;

- optimization of the tax system and the creation of conditions for increasing the investment activity of private entrepreneurs;

- the creation of special funds that finance investment projects for waste treatment;

- the acquisition by the state of equipment, machinery and mechanisms with their subsequent leasing to operating companies;

- creation of conditions for overcoming the lack of productive working capital;

- management of waste processing enterprises on the principles of strategic planning;

- effective use of depreciation and retained earnings;

- attraction of additional funds for the technical re-equipment of waste-processing enterprises and the organization of the production of competitive secondary products;

- the use of such a management method as "project management", which allows creating an effective system of organization and management based on the functional integration of all participants in the waste-processing sector of the region, linking their activities in terms of volume, time and place;

- development of a stable regulatory framework, streamlining the relationship of all subjects of waste management among themselves, with government agencies and foreign partners.

The effective functioning of a public-private partnership should be based on the use of a system analysis that ensures the adoption of rational decisions aimed at the further development of the system, including the improvement of legislative and regulatory support of the waste-processing industry.

\section{Conclusions}

Construction waste management is a very large-scale and complex task, the solution of which depends on the coherence and effectiveness of the interaction of federal, regional, municipal authorities with representatives of waste processing and construction enterprises, as well as participants in the investment field of activity. Reserves for increasing the level of efficiency of waste flow management can be found in the application of modern information technologies (BIM) and their adaptation to resource saving tasks.

The development of proposed research directions to improve the management of construction and demolition waste is an important measure aimed at obtaining environmental and economic benefits in the future.

\section{References}

1. S. Ulubeyli, A. Kazaz, V. Arslan. Modern Building Materials, Structures and Techniques. 172, 1190 (2017)

2. B. Huang, X. Wang, H. Kua, Y. Geng, R. Bleischwitz, J. Reng. Resources, Conservation and Recycling. 129, 36 (2018) 
3. A. Aleksanin. MATEC Web of Conferences. 196, 04081 (2018)

4. J. Galvez-Martos, D. Styles, H. Schoenberger, B. Zeschmar-Lahle. Resources, Conservation and Recycling. 136, 166 (2018)

5. A. Akhtar, A. K. Sarmah. Jornal of Cleaner Production. 186, 262 (2018)

6. A. Aleksanin. Industrial and Civil Engineering. 9, 77 (2017)

7. A. Aleksanin, S. Sborshikov. IOP Conf. Series: Materials Science and Engineering. 365, 062006 (2018)

8. Y. Zharov. Industrial and Civil Engineering. 5, 69 (2013)

9. J. Cheng, L. Ma. Waste Management. 33, 1539 (2013)

10. Z. Wu, A. Yu, L. Shen, G. Liu. Waste Management. 34, 1683 (2014)

11. U. Pupphachai, C. Zuidema. Ecological Indicators. 72, 784 (2017)

12. Y. Zharov. Scientific review. 10-2, 242 (2015)

13. C. Rodrigues, F. Freire. Journal of Cleaner Production. 157, 94 (2017)

14. A. Aleksanin. IOP Conf. Series: Materials Science and Engineering. 365, 062011 (2018)

15. A. Aleksanin. Scientific review. 5, 12 (2017)

16. State report "On the state and protection of the environment of the Russian Federation in 2017" (2018)

17. Report "On the state of the environment in the city of Moscow in 2017" (2018)

18. Report "Sustainable construction and demolition waste management in Abu Dhabi" (2016)

19. Report "Monitoring of solid waste in Hong Kong" (2016)

20. A. Aleksanin, S. Sborshikov. Industrial and Civil Engineering. 2, 66 (2013)

21. A. Aleksanin. The Bulletin of BSTU named after V.G. Shukhov. 5, 94 (2014)

22. A. Aleksanin, S. Sborshikov. Vestnik MGSU. 6, 229 (2013)

23. A. Aleksanin. Scientific and technical Volga region bulletin.

24. A. Subbotin, S. Sborshikov, N. Lazareva. Vestnik MGSU. 3, 247 (2014)

25. S. Sborshikov, N. Lazareva, Y. Zharov. Vestnik MGSU. 6, 165 (2014) 